\title{
Erratum to: Adsorption of arsenic(V) by iron-oxide-coated diatomite (IOCD)
}

\author{
Yi-Fong Pan • Cary T. Chiou • Tsair-Fuh Lin
}

Published online: 26 January 2013

(C) Springer-Verlag Berlin Heidelberg 2013

\section{Erratum to: Environ Sci Pollut Res (2010) 17:1401-1410 \\ DOI 10.1007/s11356-010-0325-Z}

Because some important data were miscalculated, we have modified them as follows:

Erratum (I): 3.4.2 Simulation of PDM for adsorption kinetic data

1. Pore diffusion coefficient $\left(D_{\mathrm{p}}\right)$ is corrected as $\mathbf{3} \times \mathbf{1 0}^{-7}$ $\mathrm{cm}^{2} / \mathrm{sec}$ (original value $=1.2 \times 10^{-6} \mathrm{~cm}^{2} / \mathrm{sec}$ )

2. The correct $D_{p}$ value $\left(3 \times 10^{-7} \mathrm{~cm}^{2} / \mathrm{sec}\right)$ is also shown in Fig. 5

3. Effective tortuosity $\left(\tau / K_{\mathrm{r}}=D_{\mathrm{M}} / D_{\mathrm{p}}\right)$ is replaced by $\mathbf{3 3 . 3}$ (original value $=6.3$ )

Erratum (II): 3.4.1 Rate of adsorption

Lines 6-8: ...initial adsorption rate constant $\left(v_{0}\right)$ increased from 0.93 to $1.23 \mathbf{m g g}^{-1} \mathbf{h}^{-1}$ for IOCD-3 $\mathbf{3}_{\mathbf{0 . 4 3}}$ and from 1.53 to $2.83 \mathbf{m g g}^{-1} \mathbf{h}^{-1}$ for IOCD-2 $\mathbf{2}_{\mathbf{0 . 1 1}}$ (original statement=initial adsorption rate constant $\left(v_{\mathrm{o}}\right)$ increased from 0.93 to $1.23 \mathrm{mg} / \mathrm{g}$ for IOCD- $2_{0.11}$ and from 1.53 to $2.83 \mathrm{mg} / \mathrm{g}$ for IOCD- $3_{0.43}$

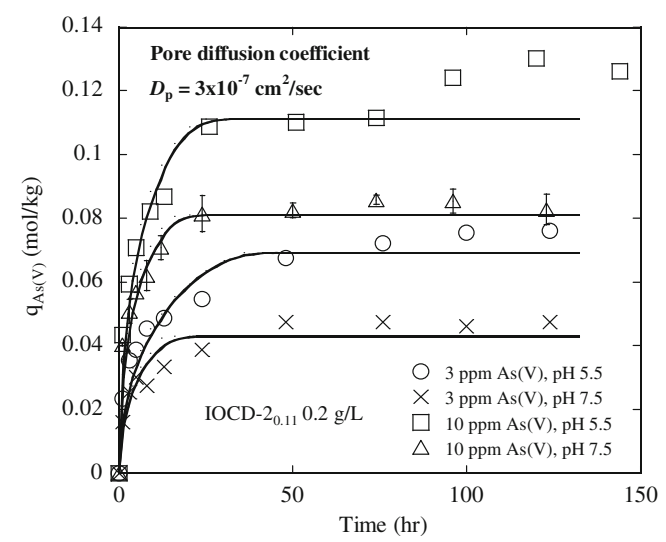

Fig. 5 Experimental data (symbols) and fitted pore diffusion model (lines) for $\mathrm{As}(\mathrm{V})$ adsorption onto IOCD $-2_{0.11}$

The online version of the original article can be found at http://dx.doi.org/ 10.1007/s11356-010-0325-z.

Y.-F. Pan $\cdot$ C. T. Chiou $\cdot$ T.-F. Lin $(\triangle)$

Department of Environmental Engineering and Sustainable

Environment Research Center, National Cheng Kung University,

Tainan City 70101, Taiwan, Republic of China

e-mail: tflin@mail.ncku.edu.tw 